\title{
Genetic Markers Associated to Dyslipidemia in HIV-Infected Individuals on HAART
}

\author{
Rosmeri K. Lazzaretti, ${ }^{1}$ Aline S. Gasparotto, ${ }^{2}$ Marina G. de M. Sassi, ${ }^{2}$ Carísi A. Polanczyk, ${ }^{1,3}$ \\ Regina Kuhmmer, ${ }^{1}$ Jussara M. Silveira, ${ }^{4}$ Rossana P. Basso, ${ }^{4}$ Cezar A. T. Pinheiro, ${ }^{5}$ \\ Mariângela F. Silveira, ${ }^{5}$ Eduardo Sprinz, ${ }^{6}$ and Vanessa S. Mattevi ${ }^{2}$ \\ ${ }^{1}$ Serviço de Cardiologia, Hospital de Clínicas de Porto Alegre, Universidade Federal do Rio Grande do Sul, \\ 90035-903 Porto Alegre, RS, Brazil \\ ${ }^{2}$ Universidade Federal de Ciências da Saúde de Porto Alegre, Rua Sarmento Leite 245, Sala 309, 90050-170 Porto Alegre, RS, Brazil \\ ${ }^{3}$ Serviço de Cardiologia, Hospital de Clínicas de Porto Alegre, Universidade Federal do Rio Grande do Sul, \\ Instituto de Avaliação de Tecnologias em Saúde, 90035-903 Porto Alegre, RS, Brazil \\ ${ }^{4}$ Hospital Universitário Dr. Miguel Riet Correa Jr., 96200-000 Rio Grande, RS, Brazil \\ ${ }^{5}$ Serviço de Assistência Especializada em HIV/AIDS, Universidade Federal de Pelotas, 96030-001 Pelotas, RS, Brazil \\ ${ }^{6}$ Serviço de Medicina Interna, Hospital de Clínicas de Porto Alegre, Universidade Federal do Rio Grande do Sul, \\ 90035-903 Porto Alegre, RS, Brazil
}

Correspondence should be addressed to Vanessa S. Mattevi; vmattevi@ufcspa.edu.br

Received 31 July 2013; Accepted 28 August 2013

Academic Editors: S. C. Fuchs, M. B. Moreira, and B. Oyeledun

Copyright (C) 2013 Rosmeri K. Lazzaretti et al. This is an open access article distributed under the Creative Commons Attribution License, which permits unrestricted use, distribution, and reproduction in any medium, provided the original work is properly cited.

This study evaluated the impact of 9 single nucleotide polymorphisms (SNPs) in 6 candidate genes (APOB, APOA5, APOE, APOC3, $S C A P$, and $L D L R$ ) over dyslipidemia in HIV-infected patients on stable antiretroviral therapy (ART) with undetectable viral loads. Blood samples were collected from 614 patients at reference services in the cities of Porto Alegre, Pelotas, and Rio Grande in Brazil. The SNPs were genotyped by conventional polymerase chain reaction (PCR) and real-time PCR. The prevalence of dyslipidemia was particularly high among the protease inhibitors-treated patients (79\%). APOE (rs429358 and rs7412) genotypes and APOA5 $-1131 \mathrm{~T}>\mathrm{C}$ (rs662799) were associated with plasma triglycerides (TG) and low-density-lipoprotein cholesterol levels (LDL-C). The $A P O A 5-1131 T>C$ (rs662799) and SCAP 2386A $>$ G (rs12487736) polymorphisms were significantly associated with high-densitylipoprotein cholesterol levels. The mean values of the total cholesterol and LDL-C levels were associated with both the APOB SP Ins/Del (rs17240441) and APOB XbaI (rs693) polymorphisms. In conclusion, our data support the importance of genetic factors in the determination of lipid levels in HIV-infected individuals. Due to the relatively high number of carriers of these risk variants, studies to verify treatment implications of genotyping before HAART initiation may be advisable to guide the selection of an appropriate antiretroviral therapy regimen.

\section{Introduction}

The use of antiretroviral therapy (ART) as a standard of care has changed the prognosis of human immunodeficiency virus (HIV) infection by decreasing mortality and improving quality of life $[1,2]$. Despite the clinical benefits, long-term ART is associated with a complex spectrum of unwanted metabolic effects, including dyslipidemia that eventually might lead to increased risk of cardiovascular diseases [3].

Nevertheless, these side effects are not universal to all individuals on ART and even vary in individuals with comparable ART, demographic, immunologic, and virological characteristics. This variability suggests that host genetic factors and inherited predispositions may have a significant influence on the appearance of metabolic alterations [4]. 
The exact mechanism of dyslipidemia is not fully understood but is most likely multifactorial. In the general population, genetic variation accounts for approximately $43 \%-$ $83 \%$ of the variability in lipid plasma levels [5]. Recent candidate gene studies [6-11] as well as genome-wide-based association studies have identified certain single nucleotide polymorphisms (SNPs) that could account for a significant portion of the variation in blood lipid levels [12-14].

In HIV infection, genetic predisposition may help to explain the variability among patients with respect to the effects of protease inhibitors (PIs) on lipid metabolism [10,11]. We have hypothesized that this variation is attributable to the joint effect of HIV infection and ART together with the underlying genetic predisposition present in these individuals. The aim of this study was to investigate the frequencies of 9 SNPs in 6 candidate genes and to identify associations between these SNPs and the plasma lipid levels of patients on stable ART with undetectable viral loads.

\section{Methods}

2.1. Subjects. We conducted a cross-sectional study with 614 patients who were diagnosed with HIV-1 infection according to the criteria of the Centers for Disease Control and Prevention [15]. All subjects were more than 17 years old, had regularly used ART for at least 12 months, had a viral load below the detection limit of the test (50 copies/mL; Versant HIV-1 RNA 3.0 Assay (bDNA), Siemens, Germany), and were recruited from three referral centers in southern Brazil (HIV/AIDS Ambulatory Unit of Hospital de Clínicas from Porto Alegre/RS, HIV Ambulatory Care of Hospital Universitário Dr. Miguel Riet Correa Jr. from Rio Grande/RS, and HIV/AIDS Specialized Assistance Service from Pelotas/RS) from March 2006 to November 2008. Pregnant women and those with neurological disease that prevented understanding and proper consent were not included in the study. The study protocol was approved by the Research Ethics Committees of the three centers and of the Universidade Federal de Ciências da Saúde de Porto Alegre, and all participants signed an informed consent statement before they were included in the study (protocol numbers: 05/295, 718/08, 154/07, and 141/06, resp.).

2.2. Study Protocol. The routine evaluation consisted of visits every 4 months in each center for an evaluation by the patients' attending physicians as well as laboratory evaluations that included measurements of CD4 cell counts, viral load, and lipid levels. The patients were invited to participate in the study and had their information and a blood sample for DNA extraction collected during one of these visits.

An interview was performed at enrollment to obtain demographic and lifestyle information. Details of HIV infection (time from diagnosis as well as current and prior antiretroviral medications), lipid-lowering intervention, and relevant clinical variables were obtained from medical records. The interviewer phenotypically defined the patients' ethnicities because there might be a strong cultural tendency to claim European ancestry in Brazil [16]. Patients were classified as Euro- or Afro-descendants because the Amerindian contribution is very low in the Brazilian South Region [17].

2.3. Laboratory Analysis. Blood samples were collected and sent to the Molecular Biology Laboratory for DNA extraction. Lipid profiles included determinations of total cholesterol (TC), high-density lipoprotein (HDL-C), triglycerides (TG), and, when possible, low-density lipoprotein (LDL-C) after fasting for 12 hours. LDL-C was calculated using the Friedewald formula, LDL-C $=\mathrm{TC}-\mathrm{HDL}-\mathrm{C}-\mathrm{TG} / 5$, if triglyceride levels were below $400 \mathrm{mg} / \mathrm{dL}$.

Dyslipidemia was defined by fasting triglycerides plasma levels $\geq 150 \mathrm{mg} / \mathrm{dL}$ and/or fasting total cholesterol $\geq 200 \mathrm{mg} / \mathrm{dL}$ and/or LDL-C $\geq 130 \mathrm{mg} / \mathrm{dL}$ and/or HDL-C $<40 \mathrm{mg} / \mathrm{dL}$. Participants were instructed not to perform any vigorous physical activity or ingest alcohol in the 24 hours prior to the blood collection [18].

Genomic DNA was obtained from peripheral leukocytes by a standard salting-out technique [19]. The genotypes of apolipoprotein $\mathrm{B}$ gene $(A P O B)$ polymorphisms were determined using polymerase chain reaction (PCR) based procedures in 410 individuals from the outpatient clinic of the Hospital de Clínicas de Porto Alegre. The polymorphism of insertion/deletion of signal peptide SP Ins/Del (rs17240441) was amplified by PCR using primers as previously described [20] and directly analyzed by electrophoresis in 8\% polyacrylamide gels. The XbaI, 7673C > T (rs693) polymorphism was amplified by PCR using the primers described by Pan et al. [21], and genotypes were determined by digestion with $\mathrm{XbaI}$ restriction endonuclease and electrophoresis in $2 \%$ agarose gels.

The SNPs of apolipoprotein A-V (APOA5) -1131T>C (rs662799) and S19W (56C>G; rs3135506), apolipoproteinE $(A P O E) 334 \mathrm{~T}>\mathrm{C}(\mathrm{E} 4 ; \mathrm{rs} 429358)$ and $472 \mathrm{C}>\mathrm{T}(\mathrm{E} 2 ; \mathrm{rs} 7412)$, apolipoprotein C-III (APOC3) 3238C > G (rs5128), sterol regulatory element-binding factor cleavage-activating protein (SCAP) 2386A > G (rs12487736), and low-density lipoprotein receptor $(L D L R)$ intron 19G>T (rs6511720) were genotyped by real-time PCR using the TaqMan methodology and are listed in Table 1. Candidate SNPs were selected via review of PubMed reports of SNP associations with dyslipidemia in the general population or among HIV-infected individuals [611].

2.4. Statistical Analyses. The results are expressed as the mean \pm standard deviation (SD) for continuous variables and as proportions for categorical variables. Variables that did not have a normal distribution (triglycerides) were transformed into natural logarithms before the statistical tests were applied. Allele frequencies were estimated by gene counting. $\chi^{2}$ analysis that was used to test for deviations in genotype frequencies from the Hardy-Weinberg equilibrium (HWE).

For the APOC3 3238C $>\mathrm{G}$ (rs5128), APOA5 -1131T>C (rs662799) and S19W (56C>G) (rs3135506), SCAP 2386A >G (rs12487736), and LDLR intron 19G $>\mathrm{T}$ (rs6511720) polymorphisms, the association analyses were performed according 
TABLE 1: Genotypic and allelic frequencies of polymorphisms analyzed.

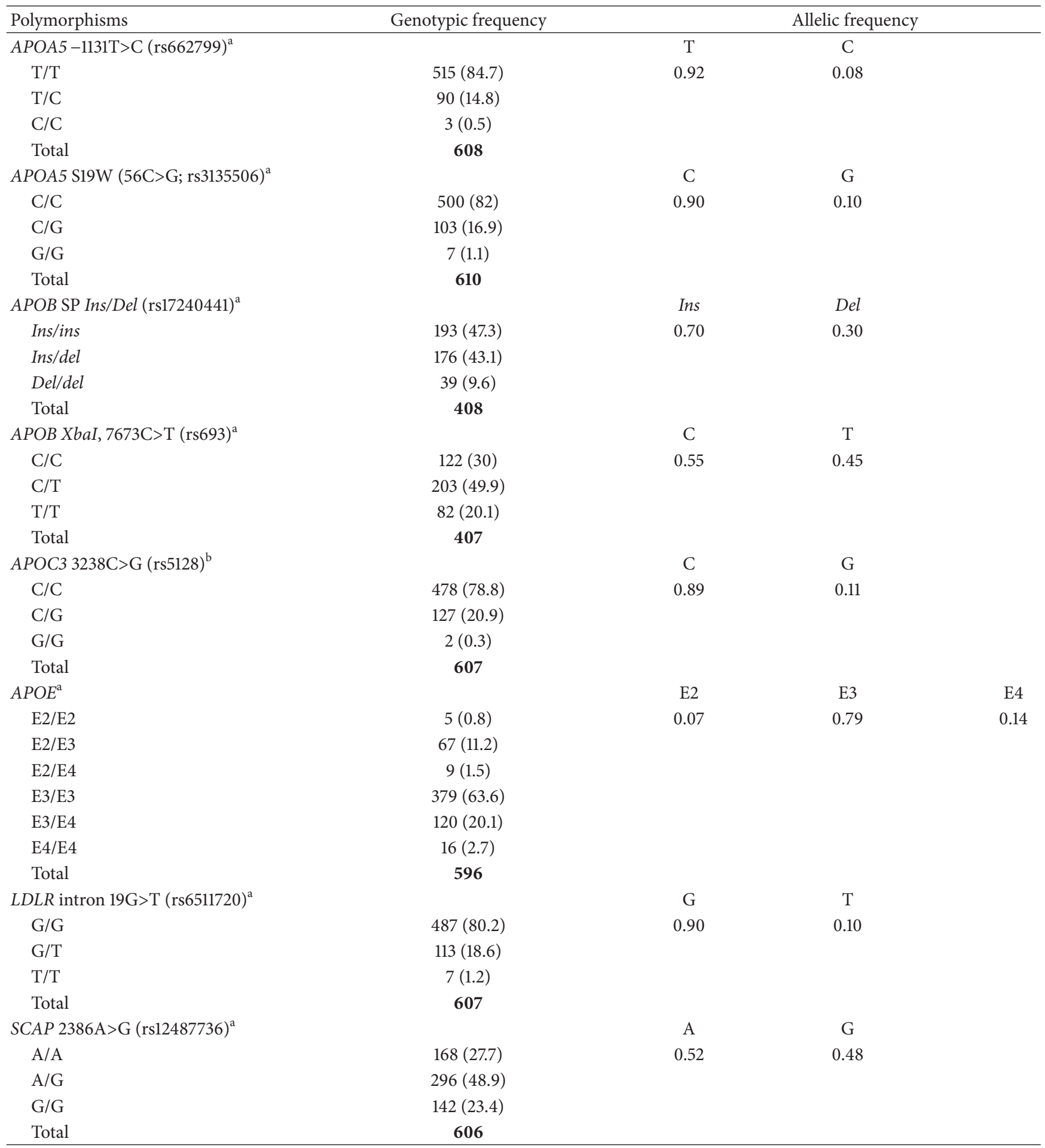

The difference in the number of individuals among single nucleotide polymorphisms (SNPs) is due to failure in genotyping some SNPs in the whole sample. Genotypic frequencies presented as number of patients (\%).

${ }^{\mathrm{a}} \chi^{2}$ test for Hardy-Weinberg equilibrium; $P>0.05$.

${ }^{\mathrm{b}} \chi^{2}$ test for Hardy-Weinberg equilibrium; $P=0.032$. 
TABLE 2: Characteristics of the study participants.

\begin{tabular}{|c|c|c|c|c|}
\hline & $\begin{array}{l}\text { All study participants } \\
\qquad n=614\end{array}$ & $\begin{array}{c}\text { PI-sparing } \\
\text { ART } \\
n=311\end{array}$ & $\begin{array}{c}\text { PI-based } \\
\text { ART } \\
n=303\end{array}$ & $P$ value \\
\hline \multicolumn{5}{|l|}{ Demographic } \\
\hline Age, years & $43.0 \pm 10$ & $42 \pm 10$ & $43 \pm 9$ & $0.114^{\S}$ \\
\hline Male sex, $n(\%)$ & $341(55.5)$ & $179(58)$ & $162(54)$ & $0.348^{*}$ \\
\hline \multicolumn{5}{|l|}{ Ethnicity, $n(\%)$} \\
\hline Euro-Brazilians & $349(57)$ & $166(48)$ & $183(60)$ & $0.094^{*}$ \\
\hline Afro-Brazilians & $265(43)$ & $145(47)$ & $120(40)$ & \\
\hline Physical activity, $n(\%)$ & $156(25)$ & $74(24)$ & $82(27)$ & $0.389^{*}$ \\
\hline Cigarette smoking, $n(\%)$ & $186(30)$ & $103(33)$ & $83(28)$ & $0.153^{*}$ \\
\hline \multicolumn{5}{|l|}{ Clinical } \\
\hline CD4, cells/uL & $533 \pm 266$ & $516 \pm 255$ & $552 \pm 277$ & $0.095^{\S}$ \\
\hline Therapy time (months) & $68 \pm 41$ & $57 \pm 38$ & $76 \pm 41$ & $<0.001^{\S ¥}$ \\
\hline Lipid-lowering drugs, $n(\%)$ & $105(17)$ & $42(14)$ & $63(21)$ & $0.021^{*}$ \\
\hline \multicolumn{5}{|l|}{ Metabolic } \\
\hline Triglycerides, mg/dL & $196 \pm 171$ & $170 \pm 131$ & $223 \pm 202$ & $<0.001^{9 ¥}$ \\
\hline Total cholesterol, mg/dL & $192 \pm 48$ & $189 \pm 44$ & $196 \pm 52$ & $0.056^{\S}$ \\
\hline $\mathrm{HDL}-\mathrm{C}, \mathrm{mg} / \mathrm{dL}$ & $48 \pm 16$ & $51 \pm 17$ & $46 \pm 14$ & $<0.001^{\S}$ \\
\hline LDL-C, mg/dL & $107 \pm 37$ & $105 \pm 34$ & $109 \pm 40$ & $0.175^{\S}$ \\
\hline Dyslipidemia, $n(\%)$ & $455(74)$ & $215(69)$ & $240(79)$ & $0.006^{*}$ \\
\hline Hypertriglyceridemia & $293(49)$ & $122(40)$ & $171(59)$ & $<0.001^{*}$ \\
\hline Hypercholesterolemia & $245(41)$ & $118(39)$ & $127(44)$ & $0.267^{*}$ \\
\hline Low HDL-C & $185(31)$ & $74(24)$ & $111(38)$ & $<0.001^{*}$ \\
\hline
\end{tabular}

Data presented as mean \pm SD or number of patients (\%).

PI: protease inhibitors; ART: antiretroviral therapy; HDL-C: high-density lipoprotein; LDL-C: low-density lipoprotein.

${ }^{¥} P$ value expressed with tests performed with $\ln$-transformed variable.

${ }^{\Im}$ Student $t$-test for independent samples.

${ }^{*} \chi^{2}$-Test with Yates correction.

Student $t$-test for independent samples with $\ln$-transformed variable.

to the dominant model due to the low number of individuals who were homozygous for the minor allele and were pooled with subjects with the heterozygous genotype. As for APOE SNPs 334T >C (rs429358) and 472C > T (rs7412), which together define the $A P O E \mathrm{E} 2, \mathrm{E} 3$, and E4 alleles, the subjects were analyzed in 3 genotype categories: E2/E3, homozygotes for the E3 allele and E3/E4. Subjects with the rare genotypes $\mathrm{E} 2 / \mathrm{E} 2(n=5), \mathrm{E} 2 / \mathrm{E} 4(n=9)$, and E4/E4 $(n=16)$ were excluded from the statistical analyses.

The Testing Haplotype Effects in Association Studies Program (version 3.1, THESIAS, Paris, France) was used for the analysis of linkage disequilibrium between polymorphisms within the same gene [22].

General linear model analyses were used to test for the interaction between SNPs and variables and to adjust the lipid profile for covariables. The following variables were included in the models and underwent stepwise removal according to the greatest $P$ values: ethnic group, gender, age, physical activity, cigarette smoking, use of lipid-lowering agents, PI use, body mass index (BMI), and the presence of polymorphism. Only those variables that were significant predictors were included in the final model. Correction for multiple testing was performed using the Bonferroni method. The data were analyzed with the Statistical Package for Social Sciences (version 20.0, SPSS, Chicago, Illinois). The value indicating statistical significance was $P<0.05$.

\section{Results}

3.1. Study Participants. The main demographic, clinical, and metabolic characteristics of the individuals enrolled in the study are shown in Table 2. Of the 614 patients, $55.5 \%$ were males, $57 \%$ were characterized as Euro-descendants, and the mean patient age was $43 \pm 10$ years. The mean duration of ART was $68 \pm 41$ months. Regarding metabolic parameters, 245 (41\%) patients had hypercholesterolemia, 293 (49\%) had hypertriglyceridemia, and 185 (31\%) had low HDL-C levels.

The total patient population was stratified according to current PI use or nonuse. The prevalence of dyslipidemia was particularly high among the PI-treated patients (79\% versus $69 \%$ in nonusers; $P=0.006)$. Although the mean levels of TC and LDL-C did not differ significantly between the PI-treated and non-PI-treated subjects, the latter had higher 
TABLE 3: Mean metabolic variables according to polymorphisms analyzed.

\begin{tabular}{|c|c|c|c|c|c|c|c|c|}
\hline \multirow[t]{2}{*}{ Polymorphisms } & \multicolumn{2}{|c|}{$\begin{array}{l}\text { Total cholesterol } \\
\qquad(\mathrm{mg} / \mathrm{dL})\end{array}$} & \multicolumn{2}{|c|}{$\begin{array}{l}\text { LDL-C } \\
(\mathrm{mg} / \mathrm{dL})\end{array}$} & \multicolumn{2}{|c|}{$\begin{array}{l}\text { HDL-C } \\
(\mathrm{mg} / \mathrm{dL})\end{array}$} & \multicolumn{2}{|c|}{$\begin{array}{l}\text { Triglycerides } \\
\text { (mg/dL) }\end{array}$} \\
\hline & $N$ & $\mathrm{M} \pm \mathrm{SD}$ & $N$ & $\mathrm{M} \pm \mathrm{SD}$ & $N$ & $\mathrm{M} \pm \mathrm{SD}$ & $N$ & $\mathrm{M} \pm \mathrm{SD}$ \\
\hline \multicolumn{9}{|c|}{ APOA5-1131T >C (rs662799) } \\
\hline $\mathrm{T} / \mathrm{T}$ & 499 & $191 \pm 80$ & 458 & $106 \pm 72$ & 498 & $48 \pm 88$ & 499 & $187 \pm 157$ \\
\hline $\mathrm{T} / \mathrm{C}+\mathrm{C} / \mathrm{C}$ & 92 & $196 \pm 78$ & 83 & $107 \pm 12$ & 92 & $45 \pm 16$ & 92 & $243 \pm 230$ \\
\hline$P$ value & & 0.549 & & 0.953 & & $0.047^{\$}$ & & $0.003^{* £}$ \\
\hline$P$ value corrected $^{* *}$ & & 1.000 & & 1.000 & & 0.376 & & 0.024 \\
\hline \multicolumn{9}{|c|}{ APOA5 S19W (56C>G; rs3135506) } \\
\hline $\mathrm{C} / \mathrm{C}$ & 486 & $192 \pm 49$ & 443 & $106 \pm 37$ & 485 & $48 \pm 15$ & 486 & $199 \pm 177$ \\
\hline $\mathrm{C} / \mathrm{G}+\mathrm{G} / \mathrm{G}$ & 106 & $197 \pm 43$ & 99 & $112 \pm 35$ & 107 & $50 \pm 17$ & 107 & $183 \pm 144$ \\
\hline$P$ value & & 0.330 & & $0.047^{\#}$ & & 0.130 & & $0.398^{*}$ \\
\hline$P$ value corrected $^{* *}$ & & 1.000 & & 0.376 & & 1.000 & & 1.000 \\
\hline \multicolumn{9}{|c|}{ APOB SP Ins/Del (rs17240441) } \\
\hline Ins/ins & 192 & $189 \pm 42^{\mathrm{a}}$ & 176 & $99 \pm 31^{\mathrm{c}}$ & 192 & $52 \pm 15$ & 193 & $195 \pm 167$ \\
\hline Ins/del & 175 & $193 \pm 51^{\mathrm{ab}}$ & 158 & $106 \pm 36^{\mathrm{cd}}$ & 175 & $50 \pm 14$ & 176 & $195 \pm 193$ \\
\hline $\mathrm{Del} / \mathrm{del}$ & 39 & $210 \pm 45^{\mathrm{b}}$ & 37 & $120 \pm 41^{\mathrm{d}}$ & 39 & $54 \pm 13$ & 39 & $187 \pm 103$ \\
\hline$P$ value & & $0.036^{\S}$ & & $0.006^{\S}$ & & 0.245 & & $0.996^{*}$ \\
\hline$P$ value corrected $^{* *}$ & & 0.288 & & 0.048 & & 1.000 & & 1.000 \\
\hline \multicolumn{9}{|c|}{$A P O B \mathrm{XbaI}, 7673 \mathrm{C}>\mathrm{T}(\mathrm{rs} 693)$} \\
\hline $\mathrm{C} / \mathrm{C}$ & 122 & $183 \pm 42^{\mathrm{e}}$ & 112 & $95 \pm 35^{\mathrm{g}}$ & 122 & $52 \pm 15$ & 122 & $187 \pm 126$ \\
\hline $\mathrm{C} / \mathrm{T}$ & 202 & $194 \pm 42^{\mathrm{ef}}$ & 185 & $107 \pm 31^{\mathrm{h}}$ & 201 & $50 \pm 14$ & 203 & $193 \pm 163$ \\
\hline $\mathrm{T} / \mathrm{T}$ & 81 & $203 \pm 59^{f}$ & 73 & $110 \pm 41^{\text {ih }}$ & 82 & $51 \pm 12$ & 82 & $212 \pm 248$ \\
\hline$P$ value & & $0.007^{\S}$ & & $0.002^{\S}$ & & 0.705 & & $0.791^{*}$ \\
\hline$P$ value corrected ${ }^{* *}$ & & 0.056 & & 0.016 & & 1.000 & & 1.000 \\
\hline \multicolumn{9}{|c|}{ APOC3 3238C > G (rs5128) } \\
\hline $\mathrm{C} / \mathrm{C}$ & 464 & $193 \pm 48$ & 424 & $107 \pm 37$ & 465 & $49 \pm 16$ & 440 & $191 \pm 162$ \\
\hline $\mathrm{C} / \mathrm{G}+\mathrm{G} / \mathrm{G}$ & 125 & $192 \pm 49$ & 115 & $108 \pm 39$ & 124 & $47 \pm 15$ & 124 & $210 \pm 214$ \\
\hline$P$ value & & 0.718 & & 0.833 & & 0.295 & & $0.905^{*}$ \\
\hline$P$ value corrected ${ }^{* *}$ & & 1.000 & & 1.000 & & 1.000 & & 1.000 \\
\hline \multicolumn{9}{|l|}{ APOE genotype } \\
\hline $\mathrm{E} 2 / \mathrm{E} 3$ & 64 & $188 \pm 60$ & 56 & $93 \pm 34^{j}$ & 63 & $46 \pm 14$ & 64 & $263 \pm 350^{1}$ \\
\hline $\mathrm{E} 3 / \mathrm{E} 3$ & 365 & $193 \pm 47$ & 333 & $109 \pm 37^{\mathrm{k}}$ & 366 & $49 \pm 16$ & 366 & $186 \pm 128^{\mathrm{m}}$ \\
\hline $\mathrm{E} 3 / \mathrm{E} 4$ & 119 & $198 \pm 47$ & 112 & $112 \pm 38^{\mathrm{k}}$ & 119 & $48 \pm 17$ & 119 & $195 \pm 153^{\mathrm{m}}$ \\
\hline$P$ value & & 0.209 & & $0.002^{9}$ & & 0.371 & & $0.033^{* \S}$ \\
\hline$P$ value corrected $^{* *}$ & & 0.836 & & 0.008 & & 1.000 & & 0.132 \\
\hline \multicolumn{9}{|c|}{$L D L R$ intron $19 \mathrm{G}>\mathrm{T}(\mathrm{rs} 6511720)$} \\
\hline $\mathrm{G} / \mathrm{G}$ & 475 & $193 \pm 48$ & 430 & $107 \pm 36$ & 476 & $48 \pm 16$ & 473 & $198 \pm 184$ \\
\hline $\mathrm{G} / \mathrm{T}+\mathrm{T} / \mathrm{T}$ & 114 & $191 \pm 51$ & 107 & $105 \pm 41$ & 113 & $50 \pm 16$ & 114 & $183 \pm 109$ \\
\hline$P$ value & & 0.612 & & 0.427 & & 0.120 & & $0.971^{*}$ \\
\hline$P$ value corrected $^{* *}$ & & 1.000 & & 1.000 & & 1.000 & & 1.000 \\
\hline
\end{tabular}


TABLe 3: Continued.

\begin{tabular}{|c|c|c|c|c|c|c|c|c|}
\hline \multirow{2}{*}{ Polymorphisms } & \multicolumn{2}{|c|}{$\begin{array}{l}\text { Total cholesterol } \\
(\mathrm{mg} / \mathrm{dL})\end{array}$} & \multicolumn{2}{|c|}{$\begin{array}{l}\text { LDL-C } \\
(\mathrm{mg} / \mathrm{dL})\end{array}$} & \multicolumn{2}{|c|}{$\begin{array}{l}\text { HDL-C } \\
(\mathrm{mg} / \mathrm{dL})\end{array}$} & \multicolumn{2}{|c|}{$\begin{array}{l}\text { Triglycerides } \\
\text { (mg/dL) }\end{array}$} \\
\hline & $N$ & $\mathrm{M} \pm \mathrm{SD}$ & $N$ & $\mathrm{M} \pm \mathrm{SD}$ & $N$ & $\mathrm{M} \pm \mathrm{SD}$ & $N$ & $\mathrm{M} \pm \mathrm{SD}$ \\
\hline \multicolumn{9}{|c|}{ SCAP 2386A $>G(r s 12487736)$} \\
\hline $\mathrm{A} / \mathrm{A}$ & 164 & $195 \pm 49$ & 146 & $107 \pm 39$ & 164 & $50 \pm 17^{\mathrm{n}}$ & 164 & $201 \pm 162$ \\
\hline $\mathrm{A} / \mathrm{G}$ & 287 & $194 \pm 48$ & 263 & $107 \pm 35$ & 287 & $49 \pm 15^{\text {no }}$ & 287 & $197 \pm 197$ \\
\hline $\mathrm{G} / \mathrm{G}$ & 137 & $188 \pm 47$ & 129 & $107 \pm 41$ & 137 & $45 \pm 14^{\mathrm{o}}$ & 138 & $188 \pm 124$ \\
\hline$P$ value & & 0.443 & & 0.970 & & $0.032^{¥}$ & & $0.971^{*}$ \\
\hline$P$ value corrected ${ }^{* *}$ & & 1.000 & & 1.000 & & 0.128 & & 1.000 \\
\hline
\end{tabular}

HDL-C: high-density lipoprotein; LDL-C: low density lipoprotein.

${ }^{*} P$ value expressed with tests performed with logn-transformed variable.

** $P$ value after Bonferroni correction for multiple testing.

${ }^{\S}$ Adjusted for gender, age, and lipid-lowering agents use.

Adjusted for age, and lipid-lowering agents use.

\$Adjusted for gender, cigarette smoking, and PI use.

${ }^{£}$ Adjusted for gender, age, lipid-lowering agents use, and PI.

\# Adjusted for gender, age, ethnic group, BMI, and lipid-lowering agents use.

${ }^{¥}$ Adjusted for gender, cigarette smoking, ethnic group, and lipid-lowering agents use.

${ }^{\mathrm{ab}}$ Tukey test, Ins/Ins versus Ins/Del, $P=0.619 ; \mathrm{Ins} /$ Ins versus $\mathrm{Del} / \mathrm{Del}, \mathrm{P}=0.027 ; \mathrm{Ins} / \mathrm{Del}$ versus $\mathrm{Del} / \mathrm{Del}, \mathrm{P}=0.145$.

${ }^{\mathrm{cd}}$ Tukey test, Ins/Ins versus Ins/Del, $P=0.231 ; \mathrm{Ins} / \mathrm{Ins}$ versus $\mathrm{Del} / \mathrm{Del}, P=0.006 ; \mathrm{Ins} / \mathrm{Del}$ versus $\mathrm{Del} / \mathrm{Del}, P=0.071$.

${ }^{\text {ef }}$ Tukey test, $\mathrm{C} / \mathrm{C}$ versus C/T, $P=0.053 ; \mathrm{C} / \mathrm{C}$ versus T/T, $P=0.007 ; \mathrm{C} / \mathrm{T}$ versus T/T, $P=0.598$.

${ }^{\text {ghi }}$ Tukey test, $\mathrm{C} / \mathrm{C}$ versus $\mathrm{C} / \mathrm{T}, P=0.006 ; \mathrm{C} / \mathrm{C}$ versus T/T, $P=0.008 ; \mathrm{C} / \mathrm{T}$ versus T/T, $P=0.830$.

${ }^{j k}$ Tukey test, E2/E3 versus E3/E3, $P=0.011$; E2/E3 versus E3/E4, $P=0.005$; E3/E3 versus E3/E4, $P=0.628$.

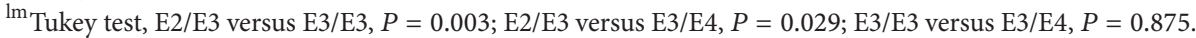

${ }^{n}$ Tukey test, $\mathrm{A} / \mathrm{A}$ versus $\mathrm{A} / \mathrm{G}, P=0.594 ; \mathrm{A} / \mathrm{A}$ versus $\mathrm{G} / \mathrm{G}, P=0.014 ; \mathrm{A} / \mathrm{G}$ versus $\mathrm{G} / \mathrm{G}, P=0.071$.

plasma HDL-C levels $(51 \pm 17 \mathrm{mg} / \mathrm{dL}$ versus $46 \pm 14 \mathrm{mg} / \mathrm{dL}$; $P<0.001)$ and lower triglycerides levels $(170 \pm 131 \mathrm{mg} / \mathrm{dL}$ versus $223 \pm 202 \mathrm{mg} / \mathrm{dL}, P<0.001)$ than the PI-treated subjects. Therefore, PI use was tested as a covariate in all statistical analyses and was included when significant.

The genotype and allele frequencies of the analyzed SNPs are shown in Table 1. For all studied polymorphisms, there was no departure from Hardy-Weinberg equilibrium, except for APOC3 3238C > G (rs5128). Table 3 summarizes the association analysis of the SNPs with serum lipid concentrations.

3.2. Triglycerides. Two SNPs contributed significantly to the modification of TG levels. The plasma TG levels were different among $A P O E$ genotypes $(P=0.033)$, the E2 allele being associated with increased TG levels (Tukey test, E2/E3 versus E3/E3, $P=0.003$; E2/E3 versus E3/E4, $P=0.029$ ). However, this result was no longer significant after correction for multiple testing $\left(P_{\text {corrected }}=0.132\right)$.

The effect of the APOA5 -1131T>C (rs662799) polymorphism on plasma lipids was observed in C-allele carriers, who presented higher triglyceride levels than those with the TT genotype $(243 \pm 230 \mathrm{mg} / \mathrm{dL}$ and $187 \pm 157 \mathrm{mg} / \mathrm{dL}$, respectively; $P=0.003$ ). This nominal $P$-value remained statistically significant after Bonferroni correction for multiple comparisons $\left(P_{\text {corrected }}=0.024\right)$.

3.3. HDL Cholesterol. The APOA5 -1131T>C (rs662799) polymorphism was also significantly associated with HDL$\mathrm{C}$ levels. The TT homozygotes presented higher HDL-C concentrations than C-carriers $(P=0.047)$ after the same statistical approach and adjustment for covariates. Furthermore, a statistically significant association of the SCAP 2386A $>\mathrm{G}$ (rs12487736) variant was observed with HDL-C levels $(P=$ 0.032 ). As shown in Table 3 , the $2386 \mathrm{GG}$ homozygotes had lower HDL-C levels, while the 2386AA homozygotes showed an increase of $5 \pm 2 \mathrm{mg} / \mathrm{dL}$ when compared to GG homozygotes (Tukey test, AA versus GG, $P=0.014$ ). However, both associations were no longer significant after the Bonferroni correction for multiple comparisons.

3.4. Total Cholesterol and LDL Cholesterol. Initially, the average TC levels were associated with both the $A P O B$ SP Ins/Del (rs17240441; Table 3, $P=0.036$ ) and $A P O B X b a \mathrm{I}$, $7673 \mathrm{C}>\mathrm{T}$ ( rs693; $P=0.007$ ) polymorphisms. The post hoc test showed that there were differences between the homozygotes for both polymorphisms (Tukey test, Ins/Ins versus Del/Del, $P=0.027$ and $\mathrm{C} / \mathrm{C}$ versus $\mathrm{T} / \mathrm{T}, P=0.007$, resp.). Neither results were significant after Bonferroni correction was applied $\left(P_{\text {corrected }}=0.320\right.$ and $P_{\text {corrected }}=0.056$, resp. $)$.

The mean LDL-C levels were also different between the genotypes $(P=0.007$ and $P=0.002$, resp.) for both polymorphisms and were statistically significant after Bonferroni correction was applied $\left(P_{\text {corrected }}=0.048\right.$ and $P_{\text {corrected }}=0.016$, resp.). The Tukey test showed that, in the polymorphism of the signal peptide, differences were found between the homozygotes (Ins/Ins versus Del/Del, $P=$ 0.006) and in the polymorphism in exon 26 of the gene the homozygous group with regard to the $\mathrm{C}$ allele differed from 
TABLE 4: Effect of $A P O B$ Del T haplotype in total cholesterol and LDL-C.

\begin{tabular}{lccccc}
\hline Risk haplotype & TC $(\mathrm{mg} / \mathrm{dL})$ & & \multicolumn{2}{c}{ LDL-C (mg/dL) } \\
& $N$ & Mean \pm SD & $P$ value & $N$ & Mean \pm SD \\
\hline Noncarriers & 213 & $188 \pm 42^{\mathrm{a}}$ & 0.036 & 196 & $100 \pm 32^{\mathrm{b}}$ \\
Heterozygous Del T & 163 & $195 \pm 51$ & & 147 & $108 \pm 36$ \\
Homozygotes Del T & 27 & $212 \pm 48^{\mathrm{a}}$ & & 25 & $118 \pm 43^{\mathrm{b}}$ \\
\hline
\end{tabular}

TC: total cholesterol; LDL-C: low density lipoprotein.

Results from analysis of variance.

${ }^{a}$ Tukey test noncarriers versus homozygous for $\operatorname{Del} \mathrm{T}, P=0.036$.

${ }^{\mathrm{b}}$ Tukey test noncarriers versus homozygous for Del T, $P=0.038$.

the other groups $(\mathrm{C} / \mathrm{C}$ versus $\mathrm{C} / \mathrm{T}, P=0.006 ; \mathrm{C} / \mathrm{C}$ versus $\mathrm{T} / \mathrm{T}$, $P=0.008)$.

A significant linkage disequilibrium $\left(D^{\prime}=0.72, P<\right.$ 0.001 ) was detected between polymorphisms associating alleles $D e l$ and T, as well as Ins and C. Based on these results, we analyzed the effect of the haplotype combining alleles $\mathrm{Del}$ and $\mathrm{T}$ on the levels of these lipid parameters. The haplotype analysis showed that homozygotes for the risk haplotype showed significantly higher mean levels of TC and LDL-C (Table 4). The post hoc test showed that the differences were found between noncarriers and homozygotes for the Del T haplotype (Tukey test, $P=0.036$ and $P=0.038$, resp.).

The APOE genotype was associated with elevated plasma LDL-C levels $\left(P=0.002 ; P_{\text {corrected }}=0.008\right.$; Table 3$)$. In contrast to what was observed regarding the TG levels, the E2 allele was associated with a decrease in the LDL-C levels, while the $\mathrm{E} 4$ allele was associated with an increase, as the differences were found between the E2 and E4 allele carriers (Tukey test, E2/E3 versus E3/E3, $P=0.011$; E2/E3 versus E3/E4, $P=0.005$ ).

Regarding APOA5 S19W (56C>G) (rs3135506), there was a marginal association with LDL-C levels. Carriers of the $\mathrm{G}$ allele and $\mathrm{C} / \mathrm{C}$ genotype showed a mean and an SD of $112 \pm 35 \mathrm{mg} / \mathrm{dL}$ and $106 \pm 37 \mathrm{mg} / \mathrm{dL}$, respectively $(P=0.047)$, that was adjusted for gender, age, BMI, and use of lipidlowering agents. However, it did not remain significant after Bonferroni correction.

No significant contribution to plasma TC, TG, HDL$\mathrm{C}$, or LDL-C was identified in the present dataset with regard to APOC3 3238C > G (rs5128) and LDLR intron 19G $>\mathrm{T}$ (rs6511720).

Analyses were also performed separately for users and nonusers of IPs (data not shown), and similar effects were observed in both groups, although in some cases these effects were not significant.

\section{Discussion}

The contributions of several polymorphisms to dyslipidemia in 614 HIV-1-infected patients on HAART were addressed in the present multicenter study. Nine polymorphisms in 6 candidate genes were analyzed for their association with dyslipidemia. As expected according to the literature, this adverse effect was more prevalent in patients receiving PIs
([23] and references therein). However, we found no statistically significant difference in TC and LDL-C levels between PI-treated and non-PI-treated patients, probably associated with the more prevalent use of lipid-lowering agents by the PI group (21 versus $14 \%, P=0.021$ ).

The allelic frequencies of the $A P O B, A P O A 5, A P O E$, $S C A P$, and $L D L R$ genotypes were similar to those previously described in populations from the same geographical region or ethnicity [8-11]. The APOC3 3238C > G (rs5128) genotypic frequencies were not distributed according to what was expected under Hardy-Weinberg equilibrium $(P=0.032$; Table 1). This small deviation was most likely due to the lower number of homozygotes ( 2 patients, $0.3 \%$ ) for the rare allele observed in our study; 7 were expected according to HardyWeinberg's proportions. Nevertheless, the allele frequencies $(G=0.11)$ were very close to those found in previous studies of individuals not infected with HIV who live in Southern Brazil $(G=0.10)$, as shown by Fiegenbaum et al. [8], and to participants in the Swiss HIV Cohort Study (SHCS), which were $G=0.10$ and $G=0.09$, as shown by Rotger et al. [11] and Tarr et al. [24], respectively.

Our study demonstrated a strong association between the E3/E4 genotype and elevated plasma LDL-C, which is in agreement with the results of previous studies $[25,26]$. The E4 variant is typically associated with increased levels of LDL-C and low plasma TG levels, whereas the $\mathrm{E} 2$ variant is associated with lower LDL-C levels in the general population $[25,26]$. In a large meta-analysis, the $\mathrm{E} 4$ variant was associated with a $42 \%$ increase in cardiovascular disease risk [27]. Although E2 isoforms bind to LDL receptors much more weakly than $\mathrm{E} 3$ or $\mathrm{E} 4$ isoforms, the catabolism of the particle containing isoform E2 is slower; this may result in a lower rate of LDL$\mathrm{C}$ formation. Moreover, according to the conclusion of the meta-analysis of Bennet et al. [28], there is an approximately linear relationship between the APOE genotypes and both LDL-C levels and to the risk of cardiovascular disease.

Carriers of non-E3/E3 genotypes of APOE appear to be at risk of ritonavir-associated hypertriglyceridemia, and this risk appears to be enhanced by the association with $A P O C 3$ variants [29]. According to the SHCS, the interaction between $A P O E$ and $A P O C 3$ is associated with an extreme risk of developing hypertriglyceridemia in individuals treated with ritonavir [24]. Our data did not allow us to perform the same analyses, as the vast majority of our PI-users were on ritonavir. Nevertheless, our findings are in agreement 
with these data reinforcing the association of E2 allele and increased TG levels. With respect to the E3/E3 genotype, according to our data as well as to those of [30], HIV-positive patients have a lower risk of developing high triglyceride levels after starting HAART than non-E3/E3 genotypes.

APOA5 also plays an important role in the modulation of blood lipid metabolism; it is predominantly synthesized in the liver and is secreted into the plasma, where it plays a central role in regulating TG metabolism [31, 32]. Two polymorphisms in the APOA5 gene, $-1131 \mathrm{~T}>\mathrm{C}$ and $\mathrm{S} 19 \mathrm{~W}$ $(56 \mathrm{C}>\mathrm{G})$, have been shown to be associated with elevated triglyceride levels in different populations [31, 33]. In our study, for APOA5 -1131T>C, individuals with at least one $C$ allele had higher TG levels and lower levels of HDLC. However, only the association with TG levels remained significant after the Bonferroni correction was applied. These results are consistent with previous study in HIV-infected patients, indicated that $-1131 \mathrm{C}$ carriers experienced marked increases in triglyceride levels during a 3-year follow-up, while no change was recorded in patients carrying the $-1131 \mathrm{~T}$ normal allele [34]. A similar effect, but of lesser magnitude, was demonstrated regarding changes in cholesterol [34].

To our knowledge, this is the first study conducted in an HIV-positive setting to assess the association of SCAP $2386 A>G$ rs12487736 with dyslipidemia. The SCAP pathway controls cellular cholesterol homeostasis. Initially, in our analysis, we found that AA homozygous patients showed higher HDL-C levels; however, this result was no longer significant after Bonferroni correction was applied. Carriers of the $2386 \mathrm{G}$ allele from non-HIV-infected Brazilians treated with simvastatin exhibit reduced TC and TG levels, as shown by Fiegenbaum et al. [7], but no association was found with HDL-C levels.

The mean TC and LDL-C levels showed statistically significant differences for genotypes of both polymorphisms in the APOB gene: SP Ins/Del (rs17240441) and XbaI, 7673C > T (rs693). The homozygotes for the alleles T and Del had higher levels of these lipids than individuals heterozygous for both alleles, who had intermediate levels; this result is compatible with a co-dominant effect of these polymorphisms. These results are in agreement with published data showing that the Del and T alleles are associated with increased levels of TC and/or LDL-C in different populations with distinct diseases [9, 35-37]. However, Xu et al. and Ye et al. found no association of the polymorphism in the signal peptide of the gene with TC and LDL-C levels in the Finnish and Chinese populations, respectively $[38,39]$.

The significant linkage disequilibrium observed between polymorphisms, as reported in other studies [20,39], led to an analysis of risk haplotype (patients with a combination of alleles Del and T). The patients who were homozygous for the risk haplotype showed higher total cholesterol and LDL$\mathrm{C}$, while an intermediate effect was observed in patients with the heterozygous haplotype. Rios et al. [9] also observed the association of the haplotype with LDL-C levels in a Brazilian population in a comparison of patients with and without coronary artery disease.

There are two possible causes for these changes in lipid metabolism related to both polymorphisms in the $A P O B$ gene. The first cause is that three amino acids, leu-ala-leu, that are included in the allele Ins and deleted in the allele Del could alter the hydrophobicity of the signal peptide of the protein and, thereby, alter the rate of translocation of new $A P O B$ peptides synthesized in the cytoplasm to the endoplasmic reticulum [38]. The second hypothesis is based on the fact that there is no amino acid change in the functional protein in both polymorphisms. These could then be in linkage disequilibrium with an unknown change in the DNA that may cause lipid abnormalities [20].

Two further SNPs that were proposed in the literature (APOC3 3238C $>\mathrm{G}$ (rs5128) and LDLR intron 19G $>\mathrm{T}$ (rs6511720) did not contribute to the plasma lipid levels in the present dataset, which may reflect a limited effect of these SNPs in HIV-infected patients.

All analyses were also performed by stratifying the patients according to PI use (data not shown); however, similar effects were observed in both groups. Furthermore, the variables were not statistically significant in some analyses, and this was most likely attributable to the reduction in the number of individuals when they are analyzed separately. This finding suggests that in our sample, the lipid-gene interaction is independent of the type of HAART used and that the variation observed is similar to that found in the general population.

We acknowledge some limitations of the present study. The cross-sectional design and the inclusion of patients receiving several different antiretroviral regimens, which is a difficulty inherent to any study involving current HAART, as by definition should include at least three different drugs. This fact might hinder the accomplishment of any pharmacogenomics study regarding this therapy. Furthermore, we found a deviation from the HWE observed in the current population for the APOC3 3238C >G (rs5128) SNP. Although this deviation may indicate genotyping error, laboratory procedures were in place to detect errors, including blinded, no-template controls and DNA sample replicates. Another limitation that we might acknowledge is the restricted number of SNPs analyzed. We cannot rule out the possibility that other SNPs in the genes investigated here are associated with the phenotypes studied.

In conclusion, our data support the importance of genetic factors on of lipid levels in HIV-infected individuals from a previously uninvestigated region of the world. We found no evidence of interaction of these genetic variants with the use of non-nucleoside transcriptase reverse inhibitors or protease inhibitors. Due to the relatively high number of carriers of these risk variants (e.g., $A P O A 5-1131 \mathrm{~T}>\mathrm{C}=15 \%, A P O B$ risk haplotype $=47 \%, A P O E=20.1 \%$ ), studies to verify treatment implications of genotyping are desirable.

\section{Authors' Contribution}

Eduardo Sprinz and Vanessa S. Mattevi were joint senior authors on this work. Aline S. Gasparotto and Marina G. de M. Sassi genotyped the patients and performed the experiments. Rosmeri K. Lazzaretti, Eduardo Sprinz, Regina Kuhmmer, Jussara M. Silveira, Rossana P. Basso, Cezar 
A. T. Pinheiro, and Mariângela F. Silveira were responsible for recruiting and clinical evaluation of patients. Vanessa S. Mattevi conceived and designed the experiments. Carísi A. Polanczyk reviewed the paper. Rosmeri K. Lazzaretti and Vanessa S. Mattevi performed the statistical analyses. Rosmeri K. Lazzaretti, Vanessa S. Mattevi, and Eduardo Sprinz wrote the paper.

\section{Disclosure}

The number of contributors is justified by the performance of sample collections and patients' evaluations in three different reference centers.

\section{Conflict of Interests}

The authors declare that there is no conflict of interests.

\section{Acknowledgments}

A special acknowledgement in memoriam of Prof. Jorge Pinto Ribeiro, an example of scientist and educator. He will be sadly missed, but his enduring and substantial legacy will be intensely alive. The authors thank Grasiela Agnes for helping with qPCR experiments. This work was supported by Departamento de DST, AIDS e Hepatites Virais, Ministério da Saúde, Brazil; Conselho Nacional de Desenvolvimento Científico e Tecnológico $(\mathrm{CNPq})$; Fundação de Amparo à Pesquisa do Estado do Rio Grande do Sul (FAPERGS); and PRONEX-FAPERGS/CNPq.

\section{References}

[1] B. O. Taiwo, X. Li, F. Palella et al., "Higher risk of AIDS or death in patients with lower CD4 cell counts after virally suppressive HAART," HIV Medicine, vol. 10, no. 10, pp. 657-660, 2009.

[2] J. R. P. Marins, L. F. Jamal, S. Y. Chen et al., "Dramatic improvement in survival among adult Brazilian AIDS patients," AIDS, vol. 17, no. 11, pp. 1675-1682, 2003.

[3] M. P. Dubé, J. H. Stein, J. A. Aberg et al., "Guidelines for the evaluation and management of dyslipidemia in human immunodeficiency virus (HIV)-infected adults receiving antiretroviral therapy: recommendations of the HIV Medicine Association of the Infectious Disease Society of America and the Adult AIDS Clinical Trials Group," Clinical Infectious Diseases, vol. 37, no. 5, pp. 613-627, 2003.

[4] J. Fox, M. Boffito, and A. Winston, "The clinical implications of antiretroviral pharmacogenomics," Pharmacogenomics, vol. 7, no. 4, pp. 587-596, 2006.

[5] M.-H. Chang, A. Yesupriya, R. M. Ned, P. W. Mueller, and N. F. Dowling, "Genetic variants associated with fasting blood lipids in the U.S. population: third National Health and Nutrition Examination Survey," BMC Medical Genetics, vol. 11, no. 1, article 62, 2010.

[6] F. M. de Andrade, S. W. Maluf, J. B. Schuch et al., "The influence of the S19W SNP of the APOA5 gene on triglyceride levels in southern Brazil: interactions with the APOE gene, sex and menopause status," Nutrition, Metabolism and Cardiovascular Diseases, vol. 21, no. 8, pp. 584-590, 2011.
[7] M. Fiegenbaum, F. R. Silveira, C. R. van der Sand et al., "Determinants of variable response to simvastatin treatment: the role of common variants of SCAP, SREBF-la and SREBF2 genes," Pharmacogenomics Journal, vol. 5, no. 6, pp. 359-364, 2005.

[8] M. Fiegenbaum, F. M. de Andrade, and M. H. Hutz, "Association between plasma lipid parameters and APOC3 genotypes in Brazilian subjects: effect of gender, smoking and APOE genotypes," Clinica Chimica Acta, vol. 380, no. 1-2, pp. 175-181, 2007.

[9] D. L. S. Rios, A. F. Vargas, M. R. Torres, A. J. Zago, S. M. Callegari-Jacques, and M. H. Hutz, "Interaction between SREBP-1a and APOB polymorphisms influences total and lowdensity lipoprotein cholesterol levels in patients with coronary artery disease," Clinical Genetics, vol. 63, no. 5, pp. 380-385, 2003.

[10] M. Arnedo, P. Taffé, R. Sahli et al., "Contribution of 20 single nucleotide polymorphisms of 13 genes to dyslipidemia associated with antiretroviral therapy," Pharmacogenetics and Genomics, vol. 17, no. 9, pp. 755-764, 2007.

[11] M. Rotger, C. Bayard, P. Taffé et al., "Contribution of genome-wide significant single-nucleotide polymorphisms and antiretroviral therapy to dyslipidemia in HIV-infected individuals: a longitudinal study," Circulation, vol. 2, no. 6, pp. 621-628, 2009.

[12] S. Kathiresan, C. J. Willer, G. M. Peloso et al., "Common variants at 30 loci contribute to polygenic dyslipidemia," Nature Genetics, vol. 41, no. 1, pp. 56-65, 2009.

[13] M. S. Sandhu, D. M. Waterworth, S. L. Debenham et al., "LDLcholesterol concentrations: a genome-wide association study," The Lancet, vol. 371, no. 9611, pp. 483-491, 2008.

[14] C. Wallace, S. J. Newhouse, P. Braund et al., "Genome-wide association study identifies genes for biomarkers of cardiovascular disease: serum urate and dyslipidemia," American Journal of Human Genetics, vol. 82, no. 1, pp. 139-149, 2008.

[15] E. Schneider, S. Whitmore, K. M. Glynn, K. Dominguez, A. Mitsch, and M. T. McKenna, "Revised surveillance case definitions for HIV infection among adults, adolescents, and children aged $<18$ months and for HIV infection and AIDS among children aged 18 months to $<13$ years-United States, 2008," Morbidity and Mortality Weekly Report, vol. 57, no. 10, pp. 1-12, 2008.

[16] V. M. Zembrzuski, S. M. Callegari-Jacques, and M. H. Hutz, "Application of an African ancestry index as a genomic control approach in a Brazilian population," Annals of Human Genetics, vol. 70, no. 6, pp. 822-828, 2006.

[17] N. P. C. Santos, E. M. Ribeiro-Rodrigues, Â. K. C. Ribeiro-dosSantos et al., "Assessing individual interethnic admixture and population substructure using a 48 -insertion-deletion (INSEL) ancestry-informative marker (AIM) panel," Human Mutation, vol. 31, no. 2, pp. 184-190, 2010.

[18] Expert Panel on Detection, Evaluation, and Treatment of High Blood Cholesterol in Adults, "Executive summary of the third report of the National Cholesterol Education Program (NCEP) expert panel on detection, evaluation, and treatment of high blood cholesterol in adults (adult treatment panel III)," Journal of the American Medical Association, vol. 285, no. 19, pp. 24862497, 2001.

[19] D. K. Lahiri and J. L. Nurnberger Jr., "A rapid non-enzymatic method for the preparation of HMW DNA from blood for RFLP studies," Nucleic Acids Research, vol. 19, no. 19, p. 5444, 1991.

[20] P. E. Pajukanta, L. M. Valsta, A. Aro, P. Pietinen, T. Heliö, and M. J. Tikkanen, "The effects of the apolipoprotein B signal peptide 
(ins/del) and XbaI polymorphisms on plasma lipid responses to dietary change," Atherosclerosis, vol. 122, no. 1, pp. 1-10, 1996.

[21] J.-P. Pan, A.-N. Chiang, J. J. Tai, S.-P. Wang, and M.-S. Chang, "Restriction fragment length polymorphisms of apolipoprotein B gene in Chinese population with coronary heart disease," Clinical Chemistry, vol. 41, no. 3, pp. 424-429, 1995.

[22] D. A. Tregouet and V. Garelle, "A new JAVA interface implementation of THESIAS: testing haplotype effects in association studies," Bioinformatics, vol. 23, no. 8, pp. 1038-1039, 2007.

[23] E. R. Feeney and P. W. G. Mallon, "HIV and HAART-associated dyslipidemia," The Open Cardiovascular Medicine Journal, vol. 5, pp. 49-63, 2011.

[24] P. E. Tarr, P. Taffe, G. Bleiber et al., "Modeling the influence of APOC3, APOE, and TNF polymorphisms on the risk of antiretroviral therapy-associated lipid disorders," Journal of Infectious Diseases, vol. 191, pp. 1419-1426, 2005.

[25] J. M. Ordovas, J. Lopez-Miranda, F. Perez-Jimenez et al., "Effect of apolipoprotein E and A-IV phenotypes on the low density lipoprotein response to HMG CoA reductase inhibitor therapy," Atherosclerosis, vol. 113, no. 2, pp. 157-166, 1995.

[26] J. Pedro-Botet, E. J. Schaefer, R. G. Bakker-Arkema et al., "Apolipoprotein E genotype affects plasma lipid response to atorvastatin in a gender specific manner," Atherosclerosis, vol. 158, no. 1, pp. 183-193, 2001.

[27] R. W. Mahley and S. C. Rall Jr., "Apolipoprotein E: far more than a lipid transport protein," Annual Review of Genomics and Human Genetics, vol. 1, no. 2000, pp. 507-537, 2000.

[28] A. M. Bennet, E. di Angelantonio, Z. Ye et al., "Association of apolipoprotein e genotypes with lipid levels and coronary risk," Journal of the American Medical Association, vol. 298, no. 11, pp. 1300-1311, 2007.

[29] J. Fauvel, E. Bonnet, J.-B. Ruidavets et al., "An interaction between apo C-III variants and protease inhibitors contributes to high triglyceride/low HDL levels in treated HIV patients," AIDS, vol. 15, no. 18, pp. 2397-2406, 2001.

[30] A. Marzocchetti, J. Schwarz, S. di Giambenedetto et al., "The effect of polymorphisms in candidate genes on the long-term risk of lipodystrophy and dyslipidemia in HIV-infected white patients starting antiretroviral therapy," AIDS Research and Human Retroviruses, vol. 27, no. 12, pp. 1299-1309, 2011.

[31] O. Seda and L. Sedova, "New Apolipoprotein A-V: comparative genomics meets metabolism," Physiological Research, vol. 52, pp. 141-146, 2003.

[32] E. S. Tai and J. M. Ordovas, "Clinical significance of apolipoprotein A5," Current Opinion in Lipidology, vol. 19, no. 4, pp. 349354, 2008.

[33] C.-Q. Lai, E.-S. Tai, C. E. Tan et al., “The APOA5 locus is a strong determinant of plasma triglyceride concentrations across ethnic groups in Singapore," Journal of Lipid Research, vol. 44, no. 12, pp. 2365-2373, 2003.

[34] M. Guardiola, R. Ferré, J. Salazar et al., "Protease inhibitorassociated dyslipidemia in HIV-infected patients is strongly influenced by the APOA5-1131T $\rightarrow$ C gene variation," Clinical Chemistry, vol. 52, no. 10, pp. 1914-1919, 2006.

[35] A. Kay, W. März, M. M. Hoffmann et al., "Coronary artery disease and dyslipidemia within Europe: genetic variants in lipid transport gene loci in German subjects with premature coronary artery disease," Atherosclerosis Supplements, vol. 3, no. 1, pp. 27-33, 2002.

[36] P. R. Turner, P. J. Talmud, S. Visvikis, C. Ehnholm, and L. Tiret, "DNA polymorphisms of the apoprotein $\mathrm{B}$ gene are associated with altered plasma lipoprotein concentrations but not with perceived risk of cardiovascular disease: european Atherosclerosis Research Study," Atherosclerosis, vol. 116, no. 2, pp. 221-234, 1995.

[37] M. Benn, B. G. Nordestgaard, J. S. Jensen, P. Grande, H. Sillesen, and A. Tybjærg-Hansen, "Polymorphism in APOB associated with increased low-density lipoprotein levels in both genders in the general population," Journal of Clinical Endocrinology and Metabolism, vol. 90, no. 10, pp. 5797-5803, 2005.

[38] C.-F. Xu, M. J. Tikkanen, J. K. Huttunen et al., "Apolipoprotein $\mathrm{B}$ signal peptide insertion/deletion polymorphism is associated with Ag epitopes and involved in the determination of serum triglyceride levels," Journal of Lipid Research, vol. 31, no. 7, pp. 1255-1261, 1990.

[39] P. Ye, B. Chen, and S. Wang, "Association of polymorphisms of the apolipoprotein B gene with coronary heart disease in Han Chinese," Atherosclerosis, vol. 117, no. 1, pp. 43-50, 1995. 


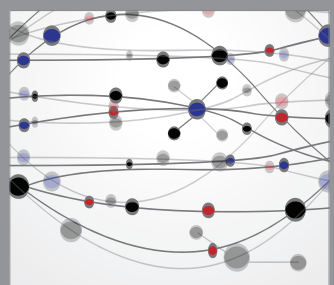

The Scientific World Journal
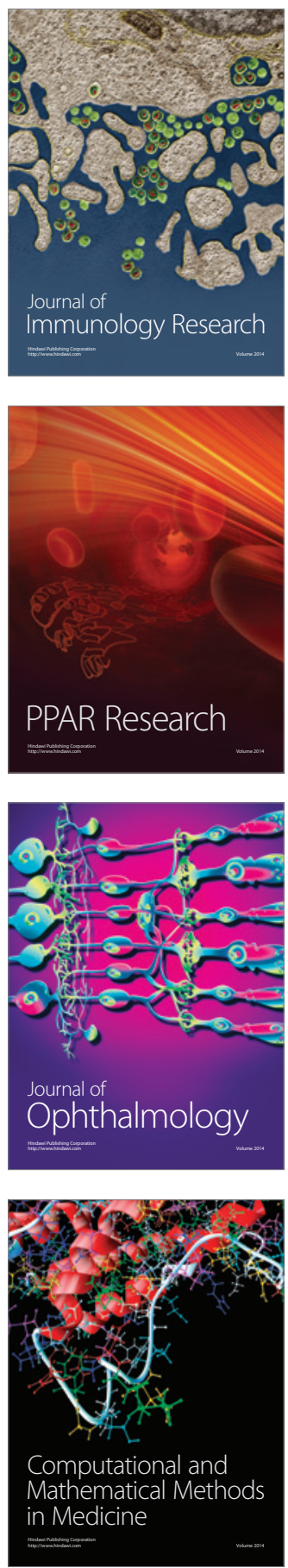

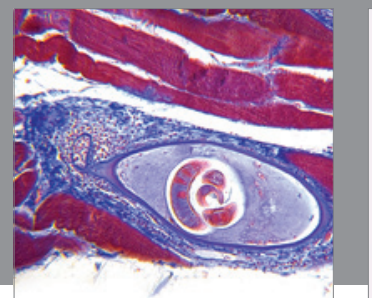

Gastroenterology

Research and Practice
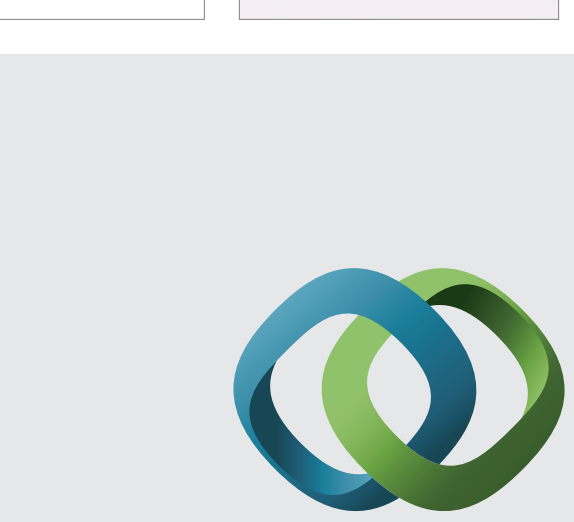

\section{Hindawi}

Submit your manuscripts at

http://www.hindawi.com
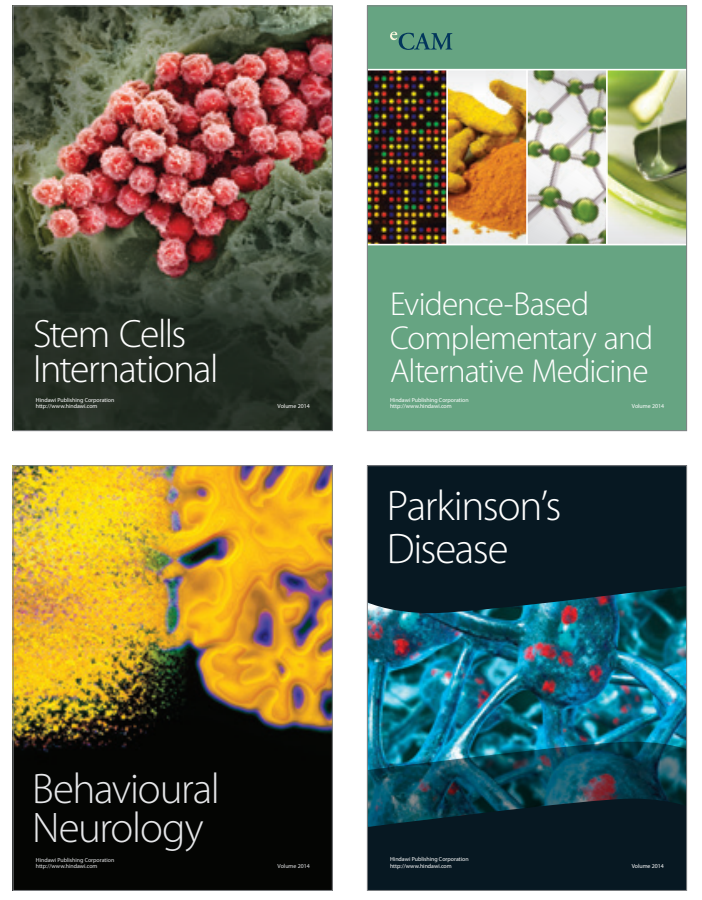
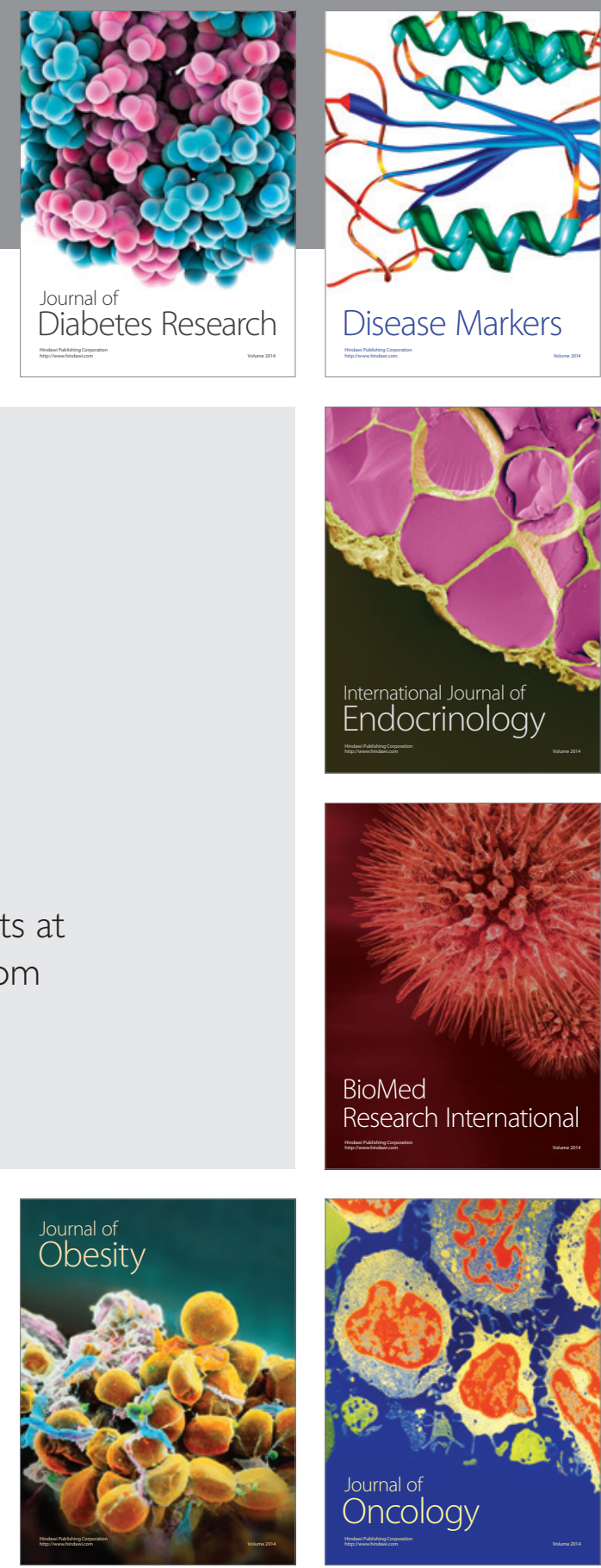

Disease Markers
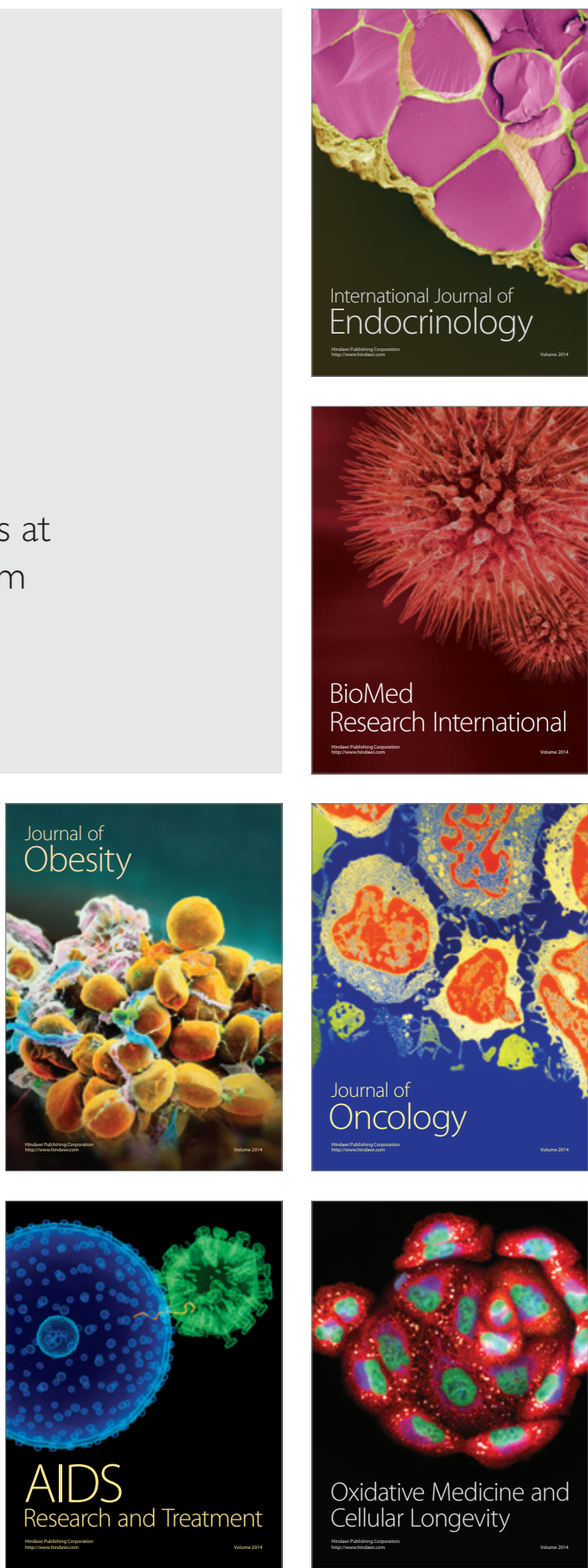